\title{
Laparoscopic surgery of the spleen through single umbilical incision
}

\author{
Michał Pędziwiatr' ${ }^{1}$ Maciej Matłok ${ }^{1}$, Piotr Major ${ }^{1}$, Daria Kuliś2 ${ }^{2}$ Andrzej Budzyński ${ }^{1}$ \\ $1^{1}{ }^{\text {nd }}$ Department of Surgery, Jagiellonian University Medical College, Krakow, Poland \\ ${ }^{2}$ General and Vascular Surgery Department, Żeromski Hospital, Krakow, Poland
}

\begin{abstract}
Introduction: Single incision transumbilical laparoscopic procedures are the next step in development of minimally invasive surgery. Recent studies prove that the new technique can be a safe alternative to multiport laparoscopy; therefore it is becoming more and more popular.

Aim: We present our preliminary experience with single incision laparoscopy of the spleen.

Material and methods: We analyse a group of 9 patients ( 7 women and 2 men) in whom we attempted single incision laparoscopic surgery of the spleen.

Results: Single incision laparoscopy was successful in all patients - in 7 of them we performed splenectomy and in 2 unroofing of the splenic cyst. Additionally, in 3 patients we performed concomitant cholecystectomy. The operative technique was identical to multiport procedures. One patient required reoperation due to intra-abdominal bleeding from the wound on the first postoperative day. In one patient due to superficial injury of the stomach wall continuous suture was used to prevent perforation. In our opinion these complications are not the result of the new technique. Conclusions: The described technique can become a safe alternative to multiport laparoscopy. It is a reasonable alternative in young patients to whom an excellent cosmetic effect is particularly important because until now it is the only documented advantage of this surgical technique.
\end{abstract}

Key words: splenectomy, minimally invasive surgery, single access.

\section{Introduction}

Laparoscopy has several indisputable advantages over open surgery regarding shorter hospital stay, faster recovery time, decreased intraoperative blood loss, wound infection rate and postoperative adhesion formation. Additionally, an improved cosmetic effect is becoming nowadays a more and more important factor for evaluation of the operation [1-3]. This approach has led surgeons to search for a technique which would allow one to perform an opera- tion that leaves no scar in the abdomen. In 1997 Navarra described single incision transumbilical cholecystectomy, which from a practical point of view fulfilled the criteria of scar-less surgery [4]. Nowadays we can observe development of the very controversial and still very futuristic idea of natural orifice transluminal endoscopic surgery (NOTES). Despite the fact that the only documented advantage of single incision laparoscopic surgery is its better cosmetic effect, the popularity of this procedure is gradually

Address for correspondence:

Andrzej Budzyński MD, PhD, 2nd Department of Surgery, Jagiellonian University Medical College, 21 Kopernika St, 31-501 Krakow, Poland, e-mail: abudzyns@cm-uj.krakow.pl 
increasing. It seems that the major reason for this fact is patients' expectations. The number of centres which offer the new operative technique is rapidly growing. Furthermore, the number of studies concerning the use of this approach is increasing.

Laparoscopic splenectomy has been considered the "gold standard" for the elective surgical management of a variety of splenic disorders [5-9]. Until now, only a few case series studies describing single incision laparoscopic surgery of the spleen have been published. The first splenectomy which used the new technique in Poland was performed in 2009 in the Institute of Haematology in Warsaw.

\section{Aim}

The aim of our study was to evaluate the preliminary experience with single incision laparoscopic transumbilical surgery in patients with splenic disorder.

\section{Material and methods}

In our clinic we have performed more than 400 laparoscopic procedures of the spleen to date. Between March 2010 and October 2011, we attempted single incision laparoscopic surgery of the spleen in 9 patients: 7 men and 2 women with a median age of 22.3 years (range: $19-34$ years) and body mass index of $23.3 \mathrm{~kg} / \mathrm{m}^{2}$ (range: $20.4-26.6 \mathrm{~kg} / \mathrm{m}^{2}$ ).

Single incision surgery was successful in all cases: in 7 of them we performed splenectomy and in 2 patients unroofing of the splenic cyst. The indications for splenectomy included haematological disorders: microspherocytosis (4 patients), idiopathic thrombocytopenic purpura (ITP) (2 patients), autoimmune haemolytic anaemia (1 patient). In 3 patients concomitant cholecystectomy (due to symptomatic cholelithiasis) with splenectomy was performed and utilized the same single transumbilical incision. In a further 2 patients we performed unroofing of the single splenic cyst (diameter 7 and $5 \mathrm{~cm}$ respectively) after exclusion of parasitic aetiology of the cyst (Table I).

Preoperative management of all patients was identical to those undergoing multiport laparoscopic splenectomy in our department. In all of them the preoperative thrombocyte count was greater than $50 \times 10^{3} / \mu l$.

\section{Operative technique}

Generally the surgical technique was designed as a direct replication of standard multiport laparoscopic operations.

Patients were operated on in the right lateral decubitus position as during the equivalent, standard laparoscopic procedure (Photo 1). The access to the peritoneal cavity was achieved under direct visual control through a $2.5-3 \mathrm{~cm}$ incision and either a SILS port ${ }^{\circledR}$ (Covidien) or a TriPort $^{\circledR}$ (Olympus) was introduced and pneumoperitoneum was established. After visual inspection of abdominal organs using a standard $10 \mathrm{~mm} 30^{\circ}$ laparoscope, working instruments were inserted. For the first operation we used flexible instruments and the remaining eight were performed with standard straight instruments.

Table I. Demographic features of the study group

\begin{tabular}{|c|c|c|c|c|c|}
\hline No. & Gender & Age [years] & $\mathrm{BMI}\left[\mathrm{kg} / \mathrm{m}^{2}\right]$ & Indication for operation & Longitudinal size of the spleen $[\mathrm{cm}]$ \\
\hline 1 & $\mathrm{~F}$ & 34 & 24.6 & ITP & 12 \\
\hline 2 & F & 23 & 22.6 & ITP & 12 \\
\hline 3 & $\mathrm{~F}$ & 22 & 23.7 & Microspherocytosis/cholelithiasis & 16 \\
\hline 4 & $\mathrm{~F}$ & 21 & 22.4 & Microspherocytosis/cholelithiasis & 17 \\
\hline 5 & F & 20 & 20.4 & Microspherocytosis/cholelithiasis & 14 (accessory spleen diameter $1 \mathrm{~cm}$ ) \\
\hline 6 & M & 20 & 26.7 & Microspherocytosis & 20 \\
\hline 7 & $\mathrm{~F}$ & 20 & 23.6 & Autoimmune haemolytic anaemia & 17 \\
\hline 8 & $M$ & 19 & 24.1 & Splenic cyst (diameter 7 cm) & 11 \\
\hline 9 & $\mathrm{~F}$ & 22 & 22.0 & Splenic cyst (diameter $5 \mathrm{~cm}$ ) & 14 \\
\hline
\end{tabular}




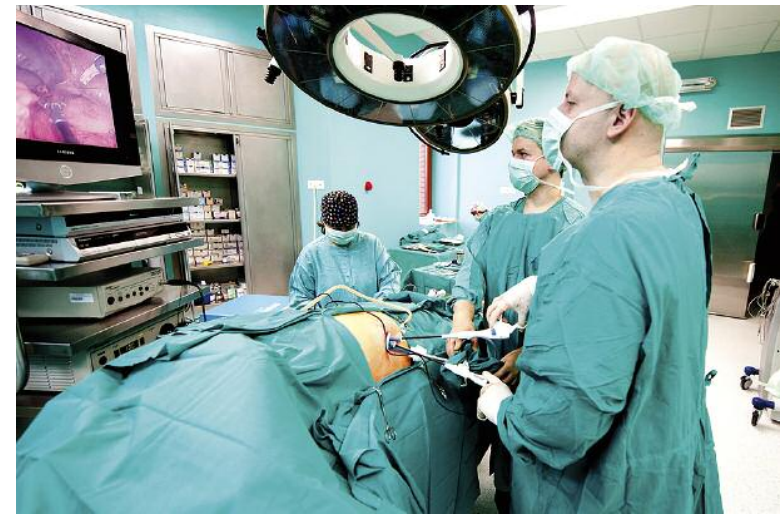

Photo 1. Patient and operating team position

The next steps of the operations were equivalent to multiport laparoscopic procedures. Opening the lesser sac and dissection of gastro-splenic ligament including short gastric vessels was performed with a harmonic scalpel (Photo 2). Later the splenic artery and vein were exposed and ligated with a clip (Photos 3,4$)$. The splenic hilum was then transected with Ligasure ${ }^{\circledR}$ (Photo 5). Patients in whom concomitant cholecystectomy was performed as a single-step procedure were then placed in a supine position and transabdominal Prolene ${ }^{\circledR}$ suture was used for better gallbladder retraction. Unroofing of the splenic cyst was performed with a harmonic scalpel. The inner lining of the cyst was cauterized with argon plasma. The incision in the abdominal wall was finally sutured with subcutaneous absorbable suture (Photo 6). We routinely do not use drains after single incision laparoscopic surgery.

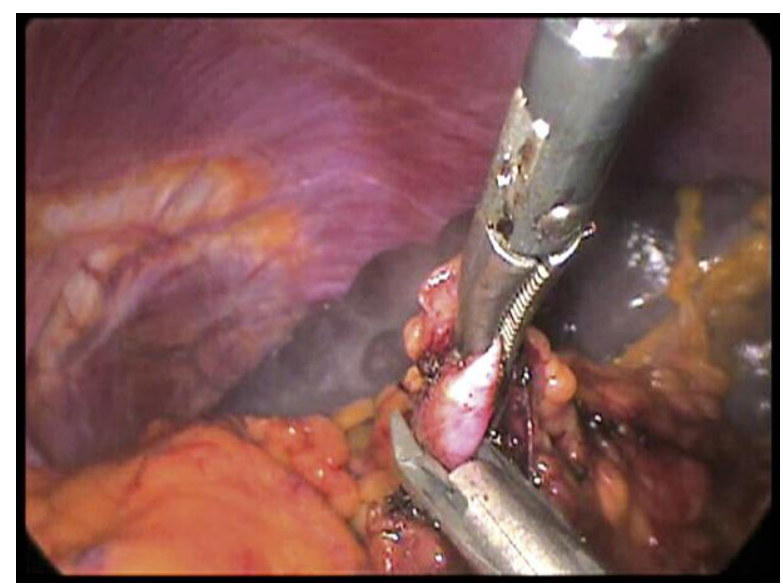

Photo 3. Clipping of splenic artery

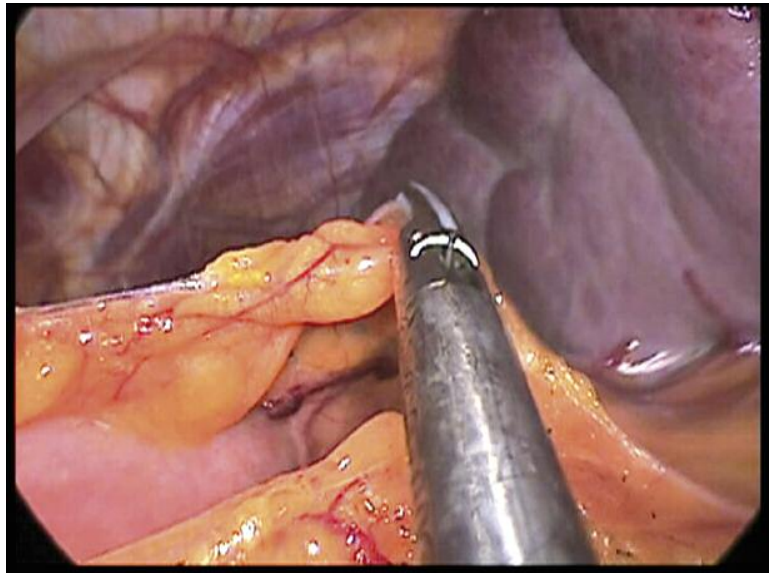

Photo 2. Dissection of short gastric vessels

\section{Results}

All procedures were successfully performed without the need to introduce additional trocars. Median splenectomy time (excluding cholecystectomy time) was 125 min (range: 80-240 min), and splenic cyst unroofing $75 \mathrm{~min}$ (50 $\mathrm{min}$ and $100 \mathrm{~min}$ ). Estimated blood loss was $35 \mathrm{ml}$ in splenectomy cases and minimal in patients undergoing splenic cyst unroofing. In 1 patient after minor superficial thermal injury of the stomach wall continuous suture was used to strengthen the injured area and prevent perforation. One patient required reoperation on the first day after surgery because of minor intra-abdominal bleeding from the wound. Explorative intervention in this patient was also performed using the single incision technique and in this case drainage was placed through an additional incision.

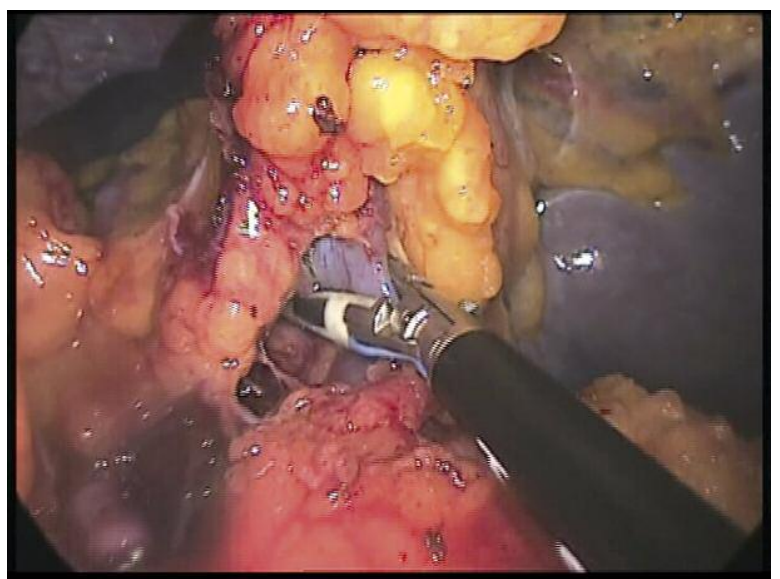

Photo 4. Sealing splenic vein with Ligasure before application of clips from $5 \mathrm{~mm}$ applier 


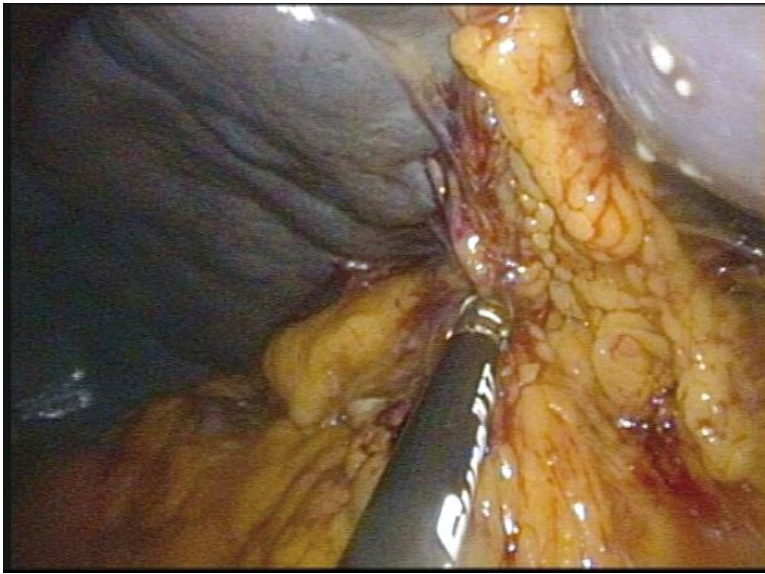

Photo 5. Dissection of splenic hilum

\section{Discussion}

Nowadays, the cosmetic effect has become one of the major factors for evaluation of the operation. Expectations of patients, especially those well educated thanks to wide access to medical knowledge and the Internet, are rapidly growing. Moreover, their preferences have become an important element of the decision making process before the treatment strategy has even started. On the other hand, the recently invented NOTES technique (natural orifice transluminal endoscopic surgery), leaving no scar after the procedure, is not as attractive as it previously seemed. For some authors it is rather a dead end in development of minimally invasive surgery [10-12]. Therefore, as regards the cosmetic result, single incision laparoscopic transumbilical surgery is widely accepted to be a safe alternative to multiport laparoscopy. After the first report of Navarra many similar studies proving feasibility of the new technique were published [13-15]. Meanwhile the first results of successful adrenalectomy, nephrectomy, hernioplasty, as well as colon resection and bariatric procedures were released. There are also several case series of elective single incision laparoscopic splenectomy due to haematological disorders [16-21].

The first use of laparoscopic splenectomy in our institution dates back to 1998. To date we have performed more than 400 laparoscopic procedures of the spleen - elective and emergency splenectomy, partial splenectomy, splenic cyst removal and splenic artery aneurysm management. Long-lasting experience in these operations induced us to evaluate the possible use of the single incision laparoscopic

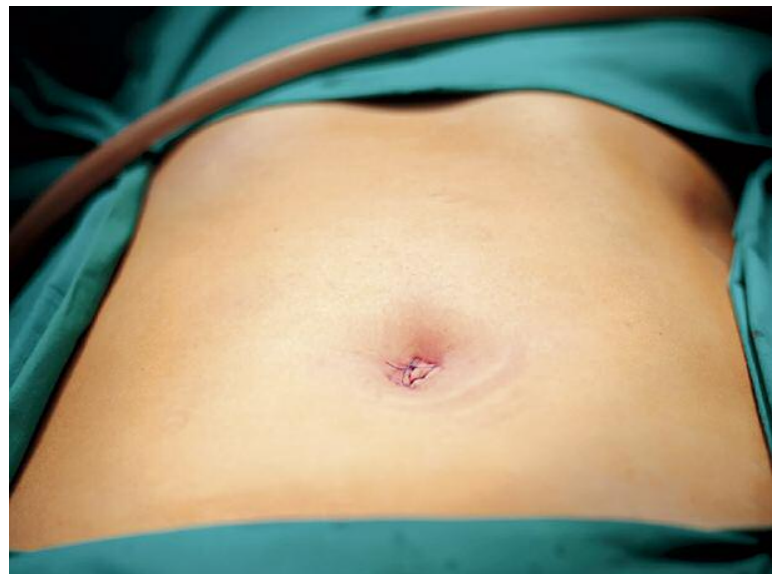

Photo 6. Umbilical wound directly after the operation

technique. Due to better cosmetic results associated with the newer technique, we included in our study young patients for whom this aspect of treatment was particularly important.

Articulating laparoscopic instruments were used only during the first operation of a very tall patient. For all remaining procedures we used straight instruments and did not find any difficulties with dissecting surrounding tissues. Generally we believe that the single incision procedure undoubtedly requires the specialized instrumentation with a flexible tip; nonetheless, it is essential only during the initial phase of learning of this technique, and an experienced surgeon will probably not need it. However, these instruments may be useful during more complex procedures.

Three patients who underwent splenectomy and cholecystectomy as a one-step procedure benefited especially from the new technique. One port placed in the umbilicus allowed for both splenectomy and cholecystectomy, thus significantly reducing the number of postoperative wounds. We believe that despite the necessity of changing the patient's position during the operation, single incision surgery is a very convenient technique in this group of patients.

In our opinion complications that resulted in our patients were not associated with the new technique and could occur in a standard multiport laparoscopy study group as well. It is worth mentioning that the reoperation in the patient with postoperative bleeding was also carried out using single incision transumbilical access. No conversions to multiport laparoscopy or open procedure is most likely a result of the highly selected group of patients with normal 
body weight and no prior surgery. However, in any case of conversion, additional trocar placement is possible so that the operation is feasible as atypical multiport laparoscopy.

Undoubtedly, single incision laparoscopic procedures require more experience in minimally invasive surgery of the spleen. Specific instrument placement running in parallel to each other and the camera requires not only excellent coordination but also full cooperation with the assistant. Therefore this technique should preferably be performed by a more experienced surgical team.

\section{Conclusions}

Single incision surgical procedures are the next step in the development of minimally invasive surgery. For an experienced surgeon this technique may become a safe alternative to classical multiport laparoscopy. It may be considered in patients for whom an excellent cosmetic effect is extremely important. Additionally, by reducing the number of wounds, it can be very convenient in patients undergoing splenectomy and cholecystectomy as a one-step operation. However, due to the small number of case reports published worldwide with relatively short observation time, the better cosmetic result is currently the only documented advantage of this surgical procedure.

\section{References}

1. Carroll B, Phillips E, Semel C, et al. Laparoscopic splenectomy. Surg Endosc 1992; 6: 183-5.

2. Katkhouda N, Hurwitz M, Rivera R, et al. Laparoscopic splenectomy: outcome and efficacy in 103 consecutive patients. Ann Surg 1998; 228: 568-78.

3. Strzałka M, Bobrzyński A, Budzyński A, et al. Open or laparoscopic appendectomy? Videosurgery Miniinv 2009; 4: 110-4.

4. Navarra G, Pozza A, Occhionorelli S, et al. One-wound laparoscopic cholecystectomy. Br J Surg 1997; 84: 695.

5. Habermalz B, Sauerland S, Decker G, et al. Laparoscopic splenectomy: the clinical practice guidelines of the European Association for Endoscopic Surgery (EAES). Surg Endosc 2008; 22: 821-48.

6. Caprotti R, Porta G, Franciosi C, et al. Laparoscopic splenectomy for hematological disorders: our experience in adult and pediatric patients. Int Surg 1998; 83: 303-7.

7. Glasgow R, Yee L, Mulvihill S. Laparoscopic splenectomy: the emerging standard. Surg Endosc 1997; 11: 108-12.

8. Bagdasarian R, Bolton J, Bowen J, et al. Steep learning curve of laparoscopic splenectomy. J Laparoendosc Adv Surg Tech 2000; 10: 319-23.
9. Delaitre B, Champault G, Barrat C, et al. Laparoscopic splenectomy for hematologic disease: study of 275 cases. French Society of Laparoscopic Surgery. Ann Chir 2000; 125: 522-9.

10. Ciesielczyk B, Cwaliński J, Janusz P. Robotic surgery and NOTES Natural Orifice Translumenal Endoscopic Surgery in treatment of cholelithiasis: revolution or failed conception. Pol Merkur Lekarski 2008; 25: 380-5.

11. Jähne J. NOTES: quo vadis? Chirurg 2010; 81: 405-6.

12. Pearl J, Ponsky J. Natural orifice translumenal endoscopic surgery: a critical review. J Gastrointest Surg 2008; 12: 1293-300.

13. Prashanth P, Pradeep P, Sonali B. Single-incision laparoscopic surgery - current status and controversies. J Minim Access Surg 2011; 7: 6-16.

14. Phillips M, Marks J, Roberts K, et al. Intermediate results of a prospective randomized controlled trial of traditional fourport laparoscopic cholecystectomy versus single-incision laparoscopic cholecystectomy. Surg Endosc 2012; 26: 1296-303.

15. Lai E, Yang G, Tang C, et al. Prospective randomized comparative study of single incision laparoscopic cholecystectomy versus conventional four-port laparoscopic cholecystectomy. Am J Surg 2011; 202: 254-8.

16. Colon M, Telem D, Chan E, et al. Laparoendoscopic single site (LESS) splenectomy with a conventional laparoscope and instruments. JSLS 2011; 15: 384-6.

17. Champagne B, Papaconstantinou H, Parmar S, et al. Single-incision versus standard multiport laparoscopic colectomy: a multicenter, case-controlled comparison. Ann Surg 2012; 255: 66-9.

18. Budzyński A, Matłok M, Pędziwiatr M, et al. SILS (single incision laparoscopic surgery) - new surgical approach to peritoneal cavity. Adv Med Sci 2011; 56: 18-24.

19. Huang C. Single-incision laparoscopic bariatric surgery. J Minim Access Surg 2011; 7: 99-103.

20. Bobowicz M, Michalik M, Orłowski M, et al. Bariatric single incision laparoscopic surgery - review of initial experience. Videosurgery Miniinv 2011; 6: 48-52.

21. Budzyński A, Pędziwiatr M, Matłok M, et al. Preliminary experience with transperitoneal single incision laparoscopic surgery adrenalectomy. Videosurgery Miniinv 2010; 5: 87-92.

Received: 9.01.2012, revised: 31.05.2012, accepted: 7.07.2012. 